\title{
Health and Sanitation Status of Bote Community
}

\author{
K. P. Rosyara \\ TU, Sigma College, Sohrakutte, Kathmandu, Nepal \\ Correspondence to: K. P. Rosyara, Sigma College Sohrakutte, Kathmandu, Nepal
}

Email: rosyara_kali@yahoo.com

\begin{abstract}
Introduction: This is a study of the health and sanitary status of Bote community, an indigenous caste of Nepal. Their Major source of income of fishing and boating and traditionally, they are less dependent on farming. Most of them stay along the riverside. There are two types of Bote; paani Bote and Pakhe Bote. Paani Botes are those who solely depend on fishing, boating, collecting motes of gold from river banks. Pakhe Bote depend more on agriculture, animal husbandry and porter for their survival. Health status and sanitation are a major problem in this community.

Methods: This is a non experimental descriptive exploratory study carried out during the period of October-November; 2009. The study population constituted 100 inhabitants of Bote community of Pragatinagar VDC of Nawalparasi district. Data was collected by on their opinion on issues such as level of health awareness, personal cleanliness, sanitation status, willingness to participate in various awareness programmes and skill development trainings.
\end{abstract}

Results: Only 15 percentages of respondents are aware of hygiene and most of them believe that ghosts spread of diseases. Most of the respondents known about family planning and immunization but there was minimal use of family planning tools and immunization (8\%).

Conclusion: Health and sanitation in this community was found to be very poor when compared to other communities of Nepal. Emphasis on health education programme should be given to improve the status of health and sanitation in this community.

Keywords: Bote community, hygiene, sanitation.

\section{Introduction}

Hygiene is defined as the science of health and includes all factors that contribute to healthful living. Health and hygiene of every human being are vital in overall development of a community and of a country in large. The problems of health and hygiene are more in the third worlds countries. As Nepal is one of the least developed countries, it faces many serious problems. Lack of sanitation is one of the most important factors in spreading up diseases. Sanitation awareness is very poor in most of the rural areas. Health is a state of complete physical, mental and social well-being not merely the absence of disease or infirmity (WHO). ${ }^{17}$ Resent government has shown commitment to provide preventive, primitive and curative health services to the people of Nepal giving priority to the rural population which comprise 85 percentage of the total population of the country. To raise health status of the people first objective of $9^{\text {th }}$ five year plan (1977-2001) was to improve the health status particularly of those whose health needs are not often met, are under privileged, especially women children and the rural population ${ }^{8}$. It was sought by strengthening primitive, preventive, curative and rehabilitative health care services. ${ }^{10}$ 
Though they are commonly called Bote in Terai, they are also referred to as Majhi and also occasionally as Kushar. Though they are known as Majhi, Bote and Kushar in different places, they speak the same language and follow similar patterns of life. Nepal is a country of extreme diversity in terms of ethnicity, language, religion, culture as well as topography. According to the 1991census, there are more than 62 castes ethnic groups and 20 major languages in Nepal. ${ }^{8}$ Diversity exits in every aspect, so it is a model of mosaic in reality. Nepal is a garden of all castes and ethnic groups each having its own tradition, culture, language and religious beliefs that are playing a vital role in national culture and nation building activities. There are many indigenous people in the country and they have inhabited the region for thousands of years but unfortunately, they are still marginalized and are barely surviving. They are also known as first people, natives, nomads, tribal, aborigines and minority and are still deprived from main stream of development, still adopting primitive lifestyle and barely able to meet their basic needs.

People of Nepal represent many different racial backgrounds and origin. Though they speak many different languages and observe just as many different religious beliefs and practices they are all Nepalese in their heart and minds. They therefore deserve equal attention and care by the state and since they are underprivileged, their concerns should be voiced by intellectuals and academicians to bring it to the attention of the leadership so that development works can be initiated to address their needs.

Bote who live along the riverside are an ideal group to study as they represent the underprivileged community as a whole. They lack any documentation about their originality and even the anthropologists of Nepal have failed to mention their origin. ${ }^{4}$

Health is a fundamental human right and it starts from the mother's ovum to death. It is the first and fundamental social concern that is common to all. In fact health is more important than human rights. It has considerable instrumental values in the context of development without which the progress in other sectors is unlikely to be attained. The ability of an individual to work and produce the level of skill and knowledge is determined by his level of health. Everybody realizes that his interest and ability to work to earn more and also to enjoy other benefits of life is largely determined by his health status. A healthy person is always cheerful and can do full day's work without exhaustion. So it called that health of the people is consider as a pillar of national development.

Nepal is facing various major health problems. Most of the people of the country are suffering from malnutrition, high child mortality, environmental pollution, rapid growth of population, high prevalence communicable disease, noncommunicable disease, lack of health facilities and services. The population growth of the country is alarming and naturally affects the overall development process. Maternal and child health care is a very important component of primary health care and it also determines the socioeconomic condition of the population as a whole.

Bote is an indigenous community of Nepal. They are mostly from Pragatinagar VDC and are suffering from poor economic and educational status compared to other communities of the country. Thus, the objective of this study is to find out the health status and health care practices of the Bote community of Nawalparasi which can be taken as a general representation of all the indigenous communities of the country.

\section{Methods}

It is a non experimental descriptive exploratory study carried out during the period of October-November, 2009. The study universe was Bote community of Pragatinagar VDC of Nawalparasi district, a typical settlement with Khar (thatches) and Jasta (Zine sheet) roof and stones, mud and wooden planks wall. A pre tested questionnaire schedule was used to collect data. The researcher went to the study site and filled up the questionnaire by visiting door to door with the supporting members of Bote community. Out of total 450 Bote populations, 100 were included in this study. The sample was selected by using random sampling at ward no. 1 and 3 . The status of health and sanitation was explained by questionnaires which focused on various aspects such as; level of health awareness, personal cleanliness, sanitation status, participation condition, sustainability condition, skill development training and other problems faced by them.

\section{Results}

Most of the people in this community were very young (Table 1). This might be a reflection of lack of family planning practices in the community.

Most of the respondents were not aware of health as a physical, mental and social wellbeing (Fig. 1). Out of 100 respondents only $15 \%$ were aware of good health as a physical, mental and social wellbeing; $70 \%$ opinioned good health as physical well and $15 \%$ had no knowledge about health. 
Health and Sanitation Status

Table 1: Demographic variable of Bote population

$\begin{array}{lllllll}\text { Age group } & \text { Male } & \text { Percentage } & \text { Female } & \text { Percentage } & \text { Total } & \text { Percentage } \\ 0-4 & 24 & 5.3 & 34 & 7.6 & 58 & 12.9 \\ 5-9 & 25 & 5.6 & 18 & 4.0 & 43 & 9.6 \\ 10-14 & 18 & 4.0 & 20 & 4.4 & 38 & 8.4 \\ 15-19 & 17 & 3.8 & 19 & 4.2 & 36 & 8.0 \\ 20-24 & 20 & 4.4 & 24 & 5.3 & 44 & 9.8 \\ 25-29 & 11 & 2.4 & 18 & 4.0 & 29 & 6.4 \\ 30-34 & 10 & 2.2 & 19 & 4.2 & 29 & 6.4 \\ 35-39 & 17 & 3.8 & 19 & 4.2 & 36 & 8.0 \\ 40-44 & 12 & 2.7 & 15 & 3.3 & 27 & 6.0 \\ 45-49 & 12 & 2.7 & 10 & 2.2 & 22 & 4.9 \\ 50-54 & 7 & 1.6 & 16 & 3.6 & 23 & 5.1 \\ 55-59 & 3 & 0.7 & 17 & 3.8 & 20 & 4.4 \\ 60-64 & 12 & 2.7 & 8 & 1.8 & 20 & 4.4 \\ 65-69 & 7 & 1.6 & 9 & 2.0 & 16 & 3.6 \\ 70-74 & 3 & 0.7 & 2 & 0.4 & 5 & 1.1 \\ \text { Above } 70 & 2 & 0.7 & 2 & 0.4 & 4 & 0.9 \\ \text { Total } & \mathbf{2 0 0} & \mathbf{4 4 . 9} & \mathbf{2 5 0} & \mathbf{5 5 . 4} & \mathbf{4 5 0} & \mathbf{1 0 0 . 0}\end{array}$

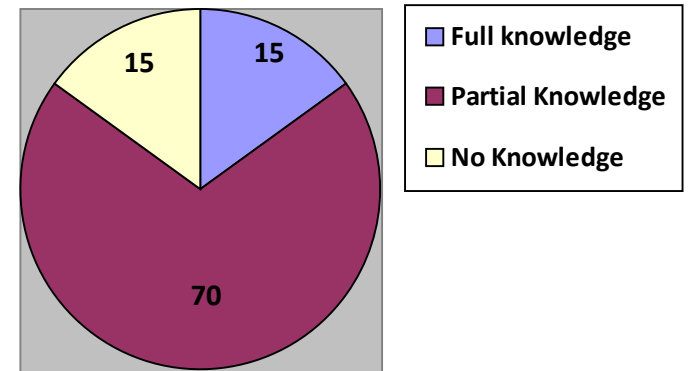

Fig. 1: Knowledge of health

People of this Bote community have diverse concepts over spreading of diseases (Fig. 2). Only 15\% respondents believed that spread of disease is the causes of environmental pollution. Majority of them replied that spreading disease is due to micro- organisms; $25 \%$ of respondents believed ghosts to be the main cause behind spread of diseases in the community and only $15 \%$ thought disease might spread by food and water.

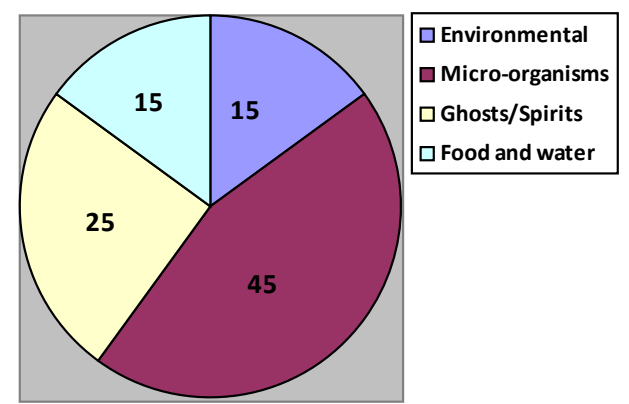

Fig. 2: Belief in spread of diseases
Most of the respondents are aware of family planning and immunization (Fig. 3). But knowledge about the use of family planning tools and immunization practice was found to be very low (8\%).

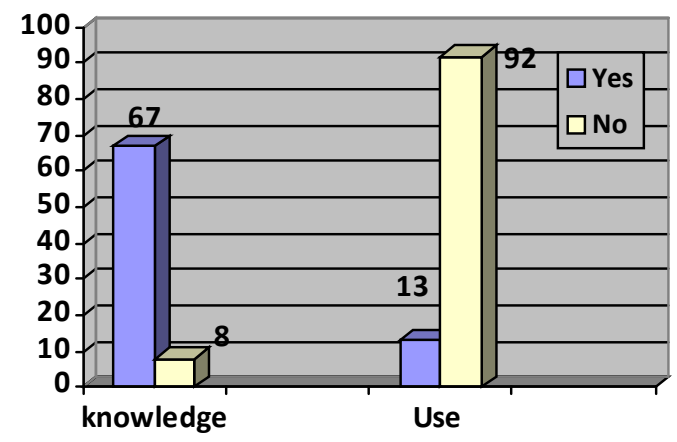

Fig. 3: Knowledge and use of family planning and immunization

In this community, out of 100 respondents only 30 percent of knew about balanced diet and malnutrition. Due to the lack of proper information regarding the community and rural health majority of respondents lack adequate knowledge about balances diet and malnutrition.

\section{Discussion}

The present study was carried out to find out the health and sanitation status of the Bote community of Nepal. Botes inhabit the banks of the Madi, Seti and Kali Gandaki and Narayani Rivers of the districts of Tanahu, Gorkha, Kaski, 
Syangja, Palpa, Gulmi, NavalParasi and Chitwan. Their religious practices, language and cultures are quite close to those of Danuwars, Darais and Majhis. Their economic activities are similar to those of the Majhi community. Botes are divided into several groups such as Mushar Bote, Kusar Bote, Kachhare Bote, Chautarae Bote, Gaurau Bote, Mukhiya Thau Bote and so on. Basically they are of two kinds - Pani (water) Botes and Pakhe (land) Botes. While the former are engaged in boating and fishing, the landbased Botes are farmers and laborers. They have their own language. They are primarily animists and use alcohol in their religious rituals; hence their religion seems different from Hinduism. Because of encroachment in their traditional occupation, they are leading a miserable life. Almost 85 percent of them are illiterates. They are also one of the endangered indigenous peoples of Nepal. According to 2001 census, their population is only 7,969.

Due to lack of knowledge about health and sanitation, many kinds of health problems are found in this community. We observed only 100 Botes out of 450 in ward no. 1 and 3 of Praganinagar VDC of Nawalparasi district.

The Study shows that there were no any differences between Panni Botes and Paakha Botes in terms of socioeconomic status. Health status of both Botes is also found to be similar in this study. There is inadequate supply of safe drinking water in the community and the housing condition is also very poor with inadequate ventilation.

Botes have their own language that belongs to the IndoEuropean family of languages. This language is in a state of being endangered. Botes have their own culture that to a great extent is similar to that of Majhi, Darai and Danuwar. Nephew or son-in-law is invited as the priest in the naming ceremony and father's sister gives a name to the child. Maternal uncle performs the first haircut of the child. Marriage is conducted either by arrangement or by mutual consent between the boy and the girl in question. Marriage is possible between the son of father's sister and the daughter of maternal uncle but marriage between the son of a maternal uncle and the daughter of father's sister (niece) is prohibited. Jaand (homemade beer), rakshi (wine/spirit), meat and bread are required in abundance during the marriage. The dead body is burried on the banks of rivers. While undergoing mourning, sons and daughters performing rites do not speak to other people other than those of their own ethnicity. They sit inside fishing nets during the mourning days. They clean themselves on the thirteenth day by washing themselves up in rivers. It is customary to break mourning on the Ghatasthapana day of Dashain.
Botes worship nature. They establish gods and goddesses in trees, stones, caves, riverbanks and worship them and sacrifice animals and birds. Most of the Botes are landless. Not even 20 per cent of them are able to afford subsistence on their own. They are traditionally engaged in rowing boats, fishing, washing gold on riverbanks (sifting gold from sand). In addition, some of them also work as agriculturists. A few of them do bamboo work to produce and sell nanglo (winnowing tray), basket, chalno (sieve), etc. Their main traditional occupation is in crisis today and they are earning their livelihood by resorting to labour work. Women are well-respected in Bote society and they are free to choose their jobs. They are encouraged to own pewapat (private property) and to do independent businesses. However, they are not entitled to a share in inherited property.

The Bote village has no separate health post. They don't have safe drinking water, personal hygiene; health knowledge, sanitation and majority of Botes of this study are illiterate. It shows 85 percentage Botes are illiterate in this community. They do not give vaccine to their child and they do not have health care practices at the time of pregnancy too. Even in the case of diarrhea also they do not have proper knowledge of treatment of giving Jeevan Jal for the solution.

\section{Conclusions}

Indigenous groups in Nepal like the Bote community are in dire need of basic health and sanitation facilities. They also need to be educated about healthy practices. Unless urgent measures to this regards are taken, the whole community of indigenous people face the risk of extinction.

\section{References}

1. Adhikari R K And Miriam K. Child nutrition and health, UNICEF, Kathmandu. $3^{\text {rd }}$ edition. 2001;1-3.

2. Basyal K P. Bote Jaati: Ek Laghu Parichya. 2038 B.S.; 32-35.

3. Bhandari D D. A Case study of socio economic status of Bote community 2045; 17-18.

4. Bista D B (1991) People of Nepal, Ratna Pustak Bhandar, Kathmandu, $1^{\text {st }}$ edition. 2004; 151-157.

5. Government of Nepal, National Planning commission secretariat, Population monograph of Nepal. Central bureau of stastics. 1991; 104-105.

6. Family health division, Maternal Mortality and Morbidity study. 1998; 6:22-33. 
7. Government of Nepal, National planning commission, , Nine ${ }^{\text {th }}$ Development plan, 2054-2059; 42-47.

8. Nepal Demographic and Health Survey 2006. Population division, Ministry of Health and Population, Government of Nepal. New ERA and Micro International Inc., Calverton, Maryland, USA, 2007; 5:133.

9. Poudel R., Natural conservationists struggle and success, Leisa India, September, 2008; 23-23.

10. Poudel Ram Chandra Health practices and its effects on health status of Tharu community, M Ed thesis. 2001; 42-45.

11. Rosyara K P and Malla B; Community health programmes for health promotion in rural community of Neal, Journal of Institute of Medicine, 2007; 29:3 32-35.

12. Rosyara K P, Acharya U and Khadka P K; Effectiveness of health insurance and its impact on rural health development, Journal of Institute of Medicine, 2006; 28:3 3-9.

13. Sharma H M. A study of Bote language, Varanashi, Prakash Printing press, 2042 B.S.; 29-32.

14. Subba S. Botes: The Ferrymen of Tanahun, National Printers, Teku, Kathmandu. $1^{\text {st }}$ edition. 1989; 7-20.

15. Thapaliya B R. Bote Jati EK Parichaya (An introduction of Bote people, 1988) 2045B.S.. Mona Thapalia, Sunsari, Nepal. P 11-44.

16. UNICEF, Nepal, Situation of Children and Women in Nepal, 2006; 10: 155-156.

17. World Health Organization, the world health report 2007; 10-14.

18. www. Janajathijapan.org.np. 2009;1-1. 